M. Fleyfel MD, ${ }^{\star} \mathrm{K}$. Bourzoufi MD, ${ }^{\star}$

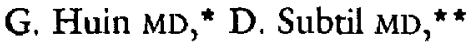

F. Puech MD PhD**

\title{
Recombinant tissue type plasminogen activator treatment of thrombosed mitral valve prosthesis during pregnancy
}

Purpose: Prosthetic heart valve thrombosis occurring during pregnancy is a life-threatening complication. Surgical treatment requires clot removal under cardiopulmonary bypass (CPB) and carries a high mortality. We describe the successful use of thrombolytic therapy for recurrent thrombosed valve prosthesis in a pregnant patient.

Clinical features: A 32-yr-old patient whose pregnancy was complicated by two episodes of a thrombosed St Jude mitral prosthesis is reported. The first episode occurred at $20 \mathrm{wk}$ of pregnancy during the change of oral anticoagulant therapy (acenocoumarol $4 \mathrm{mg}$ a day) to sc heparin. As the patient was in cardiogenic shock, the valve thrombus was treated by clot removal under CPB., with a cross clamp time of 32 min. a perfusion pressure above $70 \mathrm{mmHg}$. There was no fetal cardiac rhythm during CPB which lasted $<45 \mathrm{~min}$. The second episode occurred at the 28 th gestational week in a patient in cardiogenic shock and because reoperation was thought to carry too high a risk, the thrombus was successfully treated with $50 \mathrm{mg}$ recombinant tissue plasminogen activators (rtPA) iv. Following this, the course of pregnancy was uneventful and carried to term and the patient delivered vaginally. Pain relief was achieved with intravenous patient-controlled analgesia with alfentanil ( bolus 100 mug; lock out = five minutes). Although rtPA has been used before, this is the first report in which pregnancy was carried to term and standard vaginal delivery performed.

Conclusion: This case provides evidence for the efficacy and relative safety of rtPA as thrombolytic therapy in the treatment of haemodynamically compromised valve heart thrombosis in pregnancy.

Objectif : Rapporter un cas de thrombose d'une prothèse valvulaire de Saint-jude traitée avec succès par l'activateur du plasminogène au cours d'une grossesse.

Éléments cliniques : Nous rapportons le cas d'une parturiente âgée de 22 ans dont la grossesse a été compliquée de deux épisodes de thrombose valvulaire mitrale. Le premier épisode est survenu à la 20 e semaine lors du relais de l'anticoagulation orale (acénocoumarol $4 \mathrm{mg} \cdot \mathrm{j}^{\prime}$ ') à l'héparinisation sous-cutanée. Devant l'évidence d'un choc cardiogénique, une thrombectomie a été effectuée sous circulation extracorporelle (CEC), avec $22 \mathrm{~min}$ de clampage aortique et une pression de perfusion supérieure à $70 \mathrm{mmHg}$. Aucune anomalie du rythme foetal riest apparue au cours des $45 \mathrm{~min}$ de CEC. Le deuxième épisode est survenu à la $28^{\circ}$ semaine et a provoqué un état de choc. Parce qu'une deuxième intervention paraissait trop risquée, la thrombose a été traitée avec 50 $\mathrm{mg}$ iv de l'activateur tissulaire du plasminogène (rt-PA) avec succès. La grossesse a été menée à terme et un accouchement par voie basse a été effectué. Le traitement de la douleur obstétricale a été réalisé par analgésie autocontrôlée à l'alfentanil (bolus $100 \mu \mathrm{g}$; période réfractaire de $5 \mathrm{~min}$ ). Bien que ce traitement ait déjà été décrit, il s'agit de la première observation où une grossesse est menée à terme avec un accouchement par voie basse. Conclusion : Cette observation démontre l'intérêt et l'innocuité relative de l'activateur du plasminogène au cours de la grossesse comme alternative thérapeutique des thromboses valvulaires mécaniques.

From the Département d'Anesthésie Reanimation Chirurgicale, ${ }^{*} \mathrm{CH}$ et U - Hôpital Huriez - 59037 LILLE cedex and Service de Gynecologie Obstetrique, ${ }^{\star *} \mathrm{CH}$ et U - Hôpital Jeanne de Flandres - 59037 LILLE cedex Address correspondence to: Dr Maher Fleyfel, Departément d'Anesthésie Réanimation Chirurgicale 2

Hópital Claude Huriez, CH et U de LILLE, 59037 LILLE cedex Accepted for publication April 20, 1997. 
$\mathrm{T}$ HROMBOSIS of a prosthetic heart valve is a life threatening complication of valvular replacement which may occur despite anticoagulant therapy. ${ }^{1}$ The incidence ranges between 3 and 13\%. ${ }^{2,3}$ Pregnancy, may induce a hypercoagulable state, and an increased risk of thromboembolic disease. ${ }^{4,5}$ Although surgical management is the standard treatment for prosthetic valve thrombosis, ${ }^{3}$ in selected instances, such as a precarious cardiovascular state, fibrinolytic therapy is an alternative, especially to overcome an acute onset. We report the successful treatment of an acute obstruction of a St Jude medical prosthesis with recombinant tissue type plasminogen activator (rt-PA) in a pregnant woman who later delivered a normal healthy child vaginally.

\section{Case report}

A 32-yr-old pregnant woman, at 28 wk gestation, was admitted for acute dyspnea. Seven years ago, she had undergone mitral replacement with a St - Jude medical prosthesis for endocarditis associated with mitral valve prolapse and she was receiving digoxin and a coumarin derivative (acecoumarol $4 \mathrm{mg}$ a day). Because of the potential teratogenic effects, coumarin was replaced with sc heparin (Calciparine ${ }^{\circledR} 30 \mathrm{mg}$ three times a day) at the 6th gestational week with measurement of the partial prothrombin time (three times a week). At the 21 st week, the patient experienced acute dyspnea secondary to mitral thrombosis. Atrial thrombectomy was performed under cardiopulmonary bypass. At operation there was a thrombus arising from the base of the left atrial appendage and extending to the valve annulus. The thrombus was debrided from the valve annulus. The surgical procedure lasted for $45 \mathrm{~min}$, with a cross clamp time of 32 min. The perfusion pressure was maintained $>75$ $\mathrm{mmHg}$. No fetal heart rate disturbance was noticed. After thrombectomy, leaflet mobility was normal. She was discharged from hospital six days later in good condition receiving heparin $30 \mathrm{mg} s c$ three time a day. On readmission, physical examination revealed an afebrile patient with a respiratory rate of 25 breath $\cdot \mathrm{min}^{-1}$, a heart rate of $128 \mathrm{bpm}$, blood pressure $110 / 90 \mathrm{mmHg}$ and the extremities were cold and clammy. Auscultation of the lung revealed bilateral basal rales and of the heart decreased intensity of the valve sounds. There were no murmurs or gallops. The chest $\mathrm{X}$ ray was consistent with pulmonary oedema and the ECG revealed sinus tachycardia. Laboratory tests showed partial prothrombin time of $37 \mathrm{sec}$ (control $31 \mathrm{sec}$ ), a fibrinogen concentration of $5 \mathrm{~g} \cdot \mathrm{l}^{-1}$ and normal cardiac serum enzyme concentrations. Mitral valve thrombosis was confirmed by transoesophageal echocardiography that demonstrated restricted leaflet motion, an enclosed thrombus on the atrial surface of the prosthesis and blockage of one hemidisc in the open position. Doppler evaluation revealed a 30 $\mathrm{mmHg}$ mean gradient across the prosthesis. The use of a thrombolytic agent was proposed to avoid a second surgical debridement. After informed consent, an initial loading dose of $20 \mathrm{mg}$ plasminogen activator (rtPA) was followed by an infusion at $10 \mathrm{mg} \cdot \mathrm{hr}^{-1}$ over three hours. One hour after the initiation of the infusion the patient's general condition improved: she no longer complained of dyspnea and valve sounds were heard again. During thrombolysis global coagulation tests and fibrinogen concentrations remained within or close to the normal range. Transoesophageal echocardiography the following day revealed a mean gradient of $5 \mathrm{mmHg}$, no thrombus was visualised but the leaflet was motionless. Fluoroscopically the leaflet appeared immobile and partially open. A second regimen of five boluses of $10 \mathrm{mg}$ rtPA was administrated over five hours. At the same time an infusion of heparin $i v$ was started at $1000 \mathrm{IU} \cdot \mathrm{h}^{-1}$ and was adjusted to maintain a partial thromboplastin time of twice the normal value. Serial fluoroscopic examination revealed restoration of valve motion of the mitral valve prosthesis $24 \mathrm{hr}$ after the second regimen of fibrinolytic therapy and was confirmed by TEE. The patient experienced no major bleeding during the fibrinolytic treatment but ultrasound examination showed an anterior placental haematoma (length 40 $\mathrm{mm}$, diameter $20 \mathrm{~mm}$ ), with normal intrauterine foetal growth. Because of possible recurrence of valve thrombosis, heparin infusion was maintain at the same rate, partial prothrombin time $1.5-2 \times$ normal and the placental haematoma was observed closely by repeat ultrasound examination. The remaining course of pregnancy was uneventful: the placental haematoma spontaneously resolved at the $30 \mathrm{wk}$. Labour was induced with endocervical application of dinoprostin at $.38 \mathrm{wk}$. Heparin infusion was discontinued at the start of the labour. Once the PTT reached normal value, the patient had an artificial rupture of membranes and an oxytocin infusion. She was delivered spontaneously of a healthy girl with an Apgar score of 10 at 1 and $5 \mathrm{~min}$ at $90 \mathrm{~min}$ of uncomplicated labour. No haemorrhagic complications occurred. Analgesia was achieved using. patient-controlled analgesia with alfentanil (bolus $0.1 \mathrm{mg}$; lock-out time five minutes) and endocarditis prophylaxis with amoxicillin clavulanate. She was discharged one week after delivery receiving warfarin with a PTT of $25 \mathrm{sec}$. The predischarge TEE was consistent with normal valve motion and a normal gradient across the prothesis. 


\section{Discussion}

Thrombolytic treatment was effective in our pregnant patient with a mechanical cardiac prosthetic valve. In this report, hypercoagulability related to pregnancy and the change in the anticoagulant regiment were responsible for the first thromboembolic event. Inadequate anticoagulation protocol seemed to be the main associated factors in the second episode. Cinefluoroscopy was sufficient for the follow up of the restoration of the valve motion. A fast clot lysis specific agent, rt-PA was used for its slight impairment of plasma coagulation. ${ }^{6,7}$

Pregnancy produces a hypercoagulable state which increases the risk of thromboembolism. ${ }^{4,5}$ Artificial cardiac valves carry a high incidence of thromboembolic phenomena. Coumarin use during pregnancy is associated with an increased incidence of foetal malformation stillbirths and neonatal deaths from haemorrhage ${ }^{2,5}$ suggesting a change to heparin. However, this change increases the risk of maternal thromboembolism, ${ }^{\mathbf{8}, 9}$ including life threatening massive valve thrombosis. In non pregnant patients the tricuspid valve site provides the highest rate of thrombosis $(>20 \%),{ }^{10}$ followed, respectively, by the mitral and aortic valves ${ }^{11}$, perhaps attributed to the lower velocity of blood flow through the valve annulus, with a mortality of up to $85 \% .^{12}$

Clinical presentation may vary from minimal symptoms to life-threatening heart failure. The diagnosis is based on the change in the opening and closing sounds of the valve or the presence of a new murmur. ${ }^{11,13}$ Any worsening symptoms in a patient with a prosthetic valve should prompt a thorough investigations to exclude valve obstruction. ${ }^{11}$

Several non-invasive imaging techniques have been reported to be reliable and adjunctive methods for diagnosis of valve thrombosis. Cinefluoroscopy is a simple and rapid procedure to detect reduced leaflet motion but is of limited value when thrombus does not impede valve motion. ${ }^{14}$ Doppler transthoracic echocardiography allows the identification of non obstructive thrombi and is of major interest for quantification of prosthetic obstruction by transvalvular gradient. However, a high transvalvular gradient may be found in a normally functioning prosthesis. ${ }^{14,15}$ Today, a more accurate technique for valvular thrombosis diagnosis, is trans-oesophageal echocardiography because some echo-artefacts can cover the valve motion with the transthoracic method. ${ }^{14,15,16}$

Once the diagnosis of valve thrombosis has been established, prompt therapy is warranted. Heparin infusion might be sufficient if the thrombosis is non obstructive or the thrombus is small. ${ }^{13,14}$ Otherwise, when the thrombus is associated with a complicated course, aggressive therapy (surgery or fibrinolysis) is mandatory and the main recommended treatment is surgery involving either thrombectomy under cardiopulmonary bypass or valve replacement. However, in our case, the early recurrence of the thrombosis in a patient with poor status placed another surgery at an unacceptable risk. Thrombolytic therapy has been reported to bean effective alternative treatment and was used for the first time for a clotted Starr-Edwards prosthesis in the tricuspid position. ${ }^{17}$ Yet, fibrinolytic treatment for left-sided heart prosthesis carries a risk of systemic emboli of $18 \%$ and an overall mortality of $10 \%{ }^{18}$ Its use during pregnancy is limited because of the potential bleeding complications. Nevertheless, fibrinolytic therapy during pregnancy has been shown to be effective in treating deep venous thromboembolic episodes without any major side effect. ${ }^{19,20,21}$ There are 14 reports of thrombolytic therapy during pregnancy or in the early postpartum period for thrombosed heart valve prosthesis including our report. ${ }^{9,10,16,22-30}$ No maternal deaths have been mentioned but bleeding complications occurred in five cases. ${ }^{7,19,21,23,24}$ Several agents have been administered as fibrinolytic treatment, such as streptokinase, urokinase or rtPA at different rates. However bleeding complications have been observed with long acting fibrinolytic agents ${ }^{25,27,28}$ or longer infusion of rtPA ${ }^{23,29}$ and when used with an underlying bleeding predisposition. (i.e., soon after delivery or vaginal bleeding). Caesarean section was performed for uncontrolled haemorrhage $\mathrm{e}^{25,27}$ or ending pregnancy with therapeutic abortion to prevent recurrence of thrombosis. ${ }^{16,22,24,26,28,29}$ Systemic emboli occurred during thrombolysis in four cases but resolved spontaneously without sequelae. ${ }^{16,24,27}$

Efficacy of thrombolysis was assessed by Doppler echocardiography showing a normal gradient across the valve or by fluoroscopy with normal valve motion. Transoesophageal echocardiography may be more accurate monitor as it detects a residual non obstructive $\operatorname{clot}^{10}$ but was not evident in our case.

In conclusion, this is a report of the successful use of $\mathrm{rt} \mathrm{PA}$ in the treatment of prosthetic heart valve thrombosis without haemorrhagic complications in a pregnancy carried to term. Fibrinolysis with rtPA at low dose $(50 \mathrm{mg})$ may be an alternative to surgery in the case of pregnancy with high surgical risk.

\section{References}

1 Draur RA. Successful streptokinase therapy of prosthetic aortic valve thrombosis. Am Heart J 1984; 108: 605-6. 
2 Salazar E, Zajarias A, Gutierrez $N$, Iturbe I. The problem of cardiac valve prostheses, anticoagulants and pregnancy. Circulation 1984; 70(Suppl 1): I-169-77.

3 Kontos GJ Jr, Schaff HV. Thrombotic occlusion of a prosthetic heart valve: diagnosis and management. Mayo Clin Proc 1985; 60: 118-22.

4 Pechet $L$, Alexander $B$. Increased clotting factors in pregnancy. N Engl J Med 1961; 265: 1093-6.

5 Laros RK Jr, Alger LS. Thromboembolism and pregnancy. Clin Obstet Gynecol 1979; 22: 871-86.

6 Tischler $M$, Lee RT, Kirshenbaum JM. Successful treatment of prosthetic tricuspid valve thrombosis with short-course recombinant tissue-type plasminogen activator. Am Heart J 1990; 120: 975-7.

7 Coben $M L$, Barzilai $B$, Gutierrez $F$, Jaffe AS, Eisenberg $P$. Treatment of prosthetic tricuspid valve thrombosis wuth low-dose tissue plasminogen activator. Am Heart J 1990; 120: 978-80.

8 Ben Ismail M, Abid F, Trabelsi S, Taktak A, Fekih $M$. Cardiac valve prostheses, anticoagulation and pregnancy. Br Heart J 1986; 55: 101-5.

9 Mustapha R, Philip I, Bobm G, et al. Thromboses of heart valve prostheses: predisposing and prognostic factors based on a study of 41 patients. (French) Annales Chirurgie Thoracique et Cardio-vasculaire 1994; 48: 243-7.

10 Jost CMT, Yancy CW Jr, Ring WS. Combined thrombolytic therapy for prosthetic mitral valve thrombosis. Ann Thorac Surg 1993; 55: 159-61.

11 Deviri E, Sareli $P$, Wisenbaugh $T$, Cronje $S$. Obstruction of mechanical heart valve prostheses: clinical aspects and surgical management. J Am Coll Cardiol 1991; 17: $646-50$

12 Antunes MJ, Myer IG, Santos LP. Thrombosis of mitral valve prosthesis in pregnancy: management by simultaneous Caesarean section and mitral valve replacement. Case report. Br J Obstet Gynaecol 1984; 91: 716-8.

13 Vongpatanasin $W$, Hillis $L D$, Lange $R A$. Prosthetic heart valves. N Engl J Med 1996; 335: 407-16.

14 Habib G, Cornen A, Mesana T, Monties R, Dijane P, Luccioni $R$. Diagnosis of prosthetic heart valve thrombosis. The respective values of transthoracic and transoesophageal Doppler echocardiography. Eur Heart J 1993; 14: 447-55.

15 Gueret $P$, Vignon $P$, Fournier $P$, et al. Transesophageal echocardiography for the diagnosis and management of nonobstructive thrombosis of mechanical mitral valve prosthesis. Circulation 1995; 91: 103-10.

16 Toung E, Shapiro SM, French WJ, Ginzton LE. Use of transesophageal echocardiography during thrombolysis with tissue plasminogen activator of a thrombosed prosthetic mitral valve. J Am Soc Echocardiogr 1992; 5: 153-8.
17 Luluaga IT, Carrera D, D-Oliveira J, et al. Successful thrombolytic therapy after acute tricuspid- valve obstruction (Letter). Lancet 1971; 1: 1067-8.

18 Graver LM, Gelber PM, Tyras DH. The risks and benefits of thrombolytic therapy in acute aortic and mitral prosthetic valve dysfunction: report of a case and review of the literature. Ann Thorac Surg 1988; 46: 85-8.

$19 \mathrm{Ludwig} \mathrm{H}$. Thrombolytic therapy in pregnancy. Experimental and clinical studies. Thrombosis Diathesis Haemorrhagica 1972; 47(Suppl): 243-54.

20 Delclos GL, Davila F. Thrombolytic therapy for pulmonary embolism in pregnancy. A case report. Am J Obstet Gynecol 1986; 155: 375-6.

21 Flossdorf $T$, Breulmann $M, H o p f H B$. Successful treatment of massive pulmonary embolism with recombinant tissue type plasminogen activator (rt-PA) in a pregnant woman with intact gravidity and preterm labour. Intensive Care Med 1990; 16: 454-6.

22 Petit H, Michel JM, Thiranos JC, de Geeter B, Kieny $R$. Pulmonary valve thrombosis: echocardiographic diagnosis and thrombolytic therapy. CV World Report 1989; 2: 96-100.

23 Azzano O, French P, Robin J, et al. Thrombolytic therapy with recombinant tissue type plasminogen activator (rt-PA) for thrombosis of a tricuspid valve prosthesis during pregnancy. (French) Arch Mal Coeur Vaiss 1995; 88: 267-70.

24 Hanania $G$, Thomas $D$, Michel PL, et al. Pregnancy in patients with heart valve prostheses. A French retrospective cooperative study (155 cases). (French) Arch Mal Coeur Vaiss 1994; 87: 429-37.

25 Moisson P, Cornier E, Rozenstajn L, Catinat J. Thrombosis of a metral valve prosthesis in a pregnant woman. Treatment with streptokinase. (French) Coeur et Medecine Internet 1979; 18: 425-32.

26 Jimenez $M$, Vergnes $C$, Brottier L, et al. Reccurent thrombosis on aortic valve prosthesis during pregnancy. Results of treatment with urokinase. (French) J Mal Vasc 1988; 12: 46-9.

27 Witchitz S, Veyrat C, Moisson P, Scheinman N, Rozenstajn L. Fibrinolytic treatment of thrombus on prosthetic heart valves. Br Heart J 1980; 44: 545-54.

28 Tissot $H$, Vergnes $C$, Rougier $P$, Bricaud $H$, Dallay $D$. Therapeutic thrombolysis using urokinase steptokinase for the recurrent thrombosis in two valve prostheses for the aortic and mitral valve in pregnancy. (French) $\mathrm{J}$ Gynecol Obstet Biol Reprod 1991; 20: 1093-6.

29 Di Roio C, Perrot D, Védrinne JM, Méllier G, Robin J, Motin J. Therapeutic thrombolysis using recombinant tissue type plasminogen activator (rt-PA) for a recurrent thrombosis of a tricuspid valve prosthesis during pregnancy. (French) Ann Fr Anesth Reanim 1996; 15: 666-8. 